\title{
QUISTE ODONTOGÉNICO ORTOQUERATINIZADO
}

\author{
Agustina Ruiz ${ }^{1}$, matias torti ${ }^{1}$, and Facundo Oliva ${ }^{1}$ \\ ${ }^{1}$ Affiliation not available
}

September 12, 2020

\begin{abstract}
El quiste odontogénico ortoqueratinizado es una entidad reconocida desde 1981. Es una lesión poco frecuente, rara, asintomática, con predilección por el sexo masculino. Se presenta con mayor frecuencia en la mandíbula, en la región de los molares y la rama mandibular. No está asociado al síndrome de Gorlin-Goltz; sin embargo, se han reportado casos donde se ha evidenciado una transformación neoplásica en su capa epitelial. Radiográficamente, se observa imagen radiolúcida unilocular, no produce expansión de corticales óseas y por lo general está asociado con dientes impactados. Histológicamente, posee un epitelio ortoqueratinizado, un prominente estrato granuloso y células basales cúbicas con poca tendencia a tener núcleos polarizados. Inmunohistoquímicamente, demuestra que posee poco potencial de proliferación y actividad celular, lo que explica su poca recurrencia después de la cirugía, por lo que se sugieren alternativas de tratamiento conservadoras. Es una lesión quística no agresiva con características bien definidas; si se trata a tiempo, puede mejorar el pronóstico del paciente.
\end{abstract}

En este artículo tiene como objetivo describir las principales características del QOO y su diferenciación con el queratoquiste odontogénico.

Palabras claves: Quiste odontogénico ortoqueratinizado, odontogénico, queratina, queratoquiste odontogénico.

\section{INTRODUCCIÓN}

El quiste odontogénico ortoqueratinizado (QOO) es uno de los quistes menos frecuentes en cuanto al desarrollo dental ya que representan el $7 \%$ del $17 \%$ de todos los quistes queratinizados de la mandíbula. Tiene una mayor incidencia en hombres que en mujeres, con una relación de 3.2: 1. Predomina en pacientes adultos jóvenes, con una predilección por la tercera y cuarta década de vida, con una edad promedio de 35.4 años. Se presenta con frecuencia en la mandíbula, en la región de los molares y la rama mandibular.

Fue descrito en 1956 por Philipsen como una variante del queratoquiste odontogénico (tumor odontogénico queratinizante) y posteriormente identificado como una entidad totalmente aparte por Wrigth en 1981 debido a las variantes histologicas y al comportamiento clinico que presenta.

El QOO comparte el mismo origen que el tumor odontogenico queratoquistico (TOQQ), porque ambos presentan lesiones intraoseas de los maxilares. Su desarrollo es a partir de restos de la lamina dental. 


\section{DESARROLLO}

El quiste odontogenico ortoqueratinizado se ha clasificado como un quiste de tipo odontogenico, ya que el epitelio que reviste la luz del mismo deriva del epitelio perteneciente al germen dentario. En la actualidad ha sido considerado una variante totalmente independiente ortoqueratinizada del queratoquiste odontogenico debido a sus diferencias histologicas y su comportamiento siendo este de menor agresividad y menor grado de recurrencia.

\section{Caracteristicas histopatologicas.}

El QOO se caracteriza por presentar, una pared tapizada por un epitelio estratificado, es decir, con varias capas de celulas siendo esta delgada con un espesor promedio de cuatro a ocho celulas. La capa de celulas basales de su epitelio se encuentran mucho mas desarrolladas que el queratoquiste de forma cuboidal demostrando tener poco o casi nula polaridad o ser hipercromaticas. Siguiendo mas a la superficie del epitelio en la capa espinosa se puede observar una variabilidad en cuanto a la forma de las celulas siendo estas poliedricas o chatas, con citoplasma eosinofilo y puentes intercelulares prominentes. La capa granular esta bien desarrollada con su superficie recubierta por una queratinizacion completa de las capas superficiales llamada ortoqueratina pudiendose apreciar como en las celulas no se observan los nucleos. Existe una diferencia en cuanto la maduracion epitelial entre el quiste odontogenico ortoqueratinizado y el tumor odontogenico queratoquistico teniendo el primero una maduracion gradual y continua desde la capa basal hasta la ortoqueratina. La transicion de la capa basal a la paraqueratinizada es de manera abrupta en la mayoria de

los casos. La interfase del epitelio conectivo es llana, con una discreta membrana basal separando ambos tejidos. El tejido que forma la capsula del quiste esta constituido por un tejido conectivo denso es decir con una mayor presencia de fibras que de celulas. 


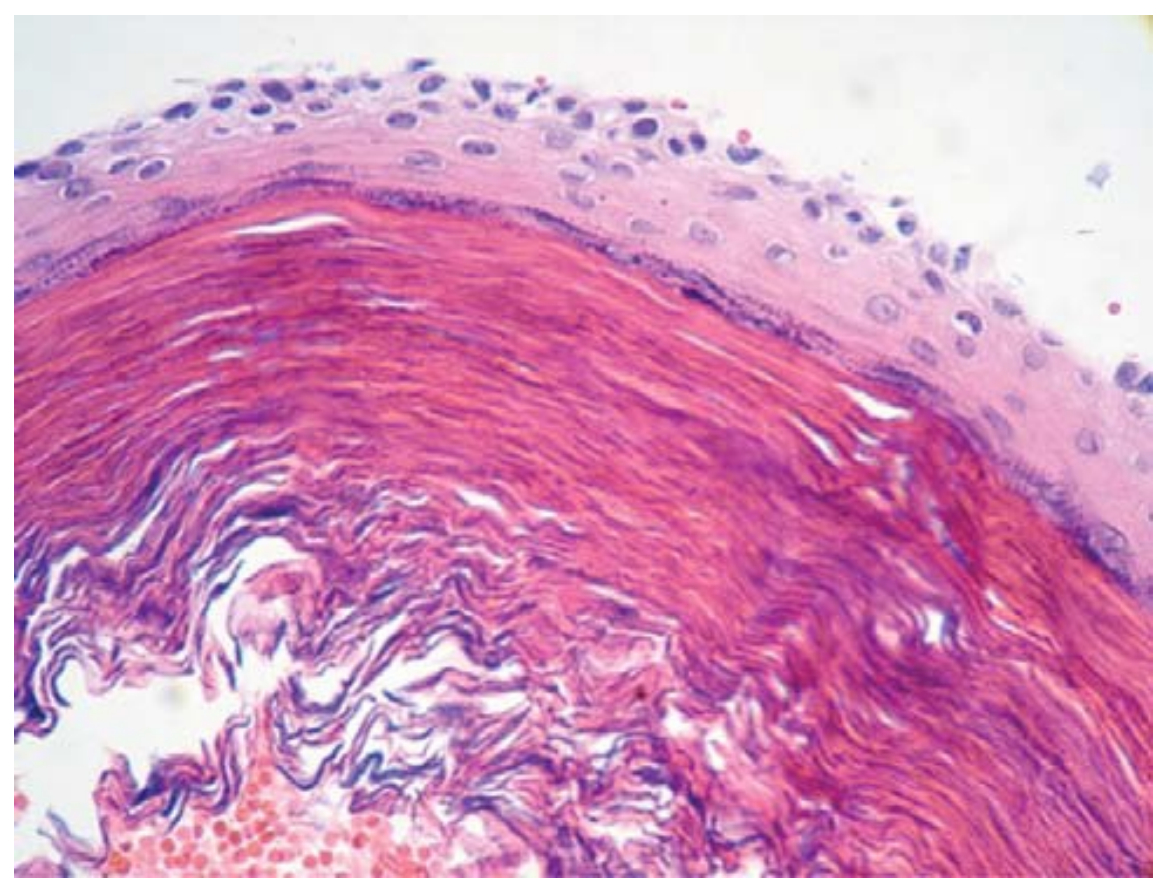

Figure 1: Imagen histológica del quiste odontogénico ortoqueratinizado.

\section{Características inmunohistoquímicas}

Diferentes estudios, demuestran que el QOO presenta características inmunohistoquímicas bien definidas, compatibles con su potencial de crecimiento limitado y su naturaleza quística.

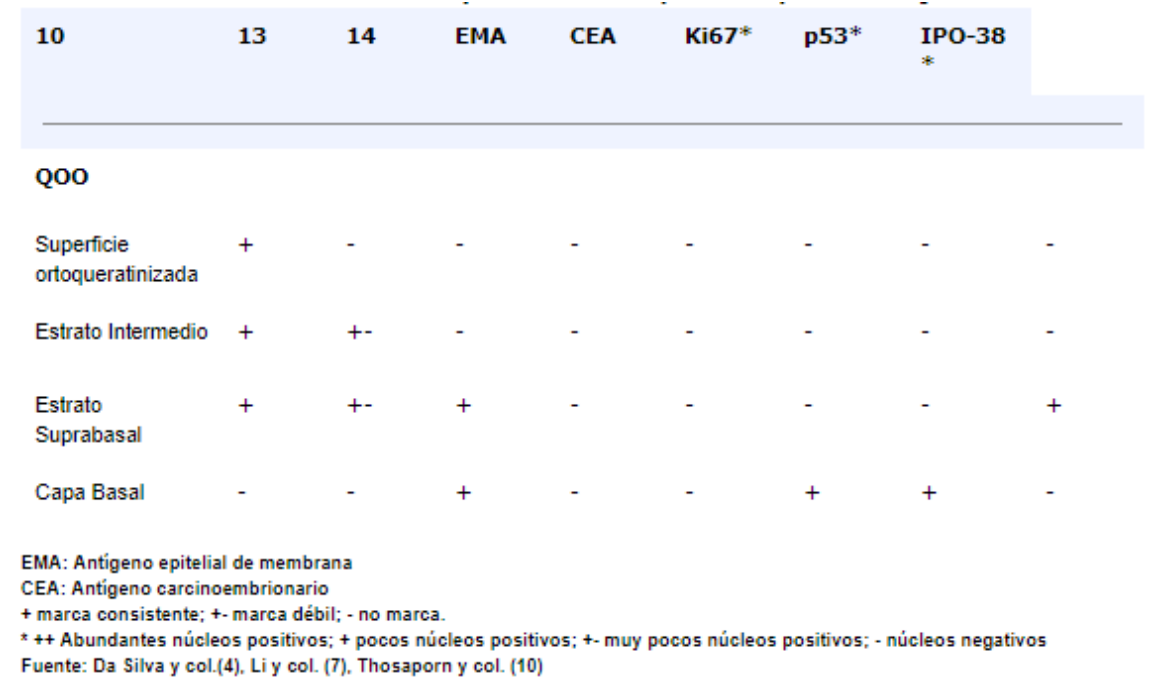

Figure 2: Tabla con las características inmunohistoquímicas del componente epitelial del QOO 


\section{Características radiográficas}

Radiográficamente se presenta como una lesión radiolúcida circunscrita de bordes bien definidos, rodeados de una cortical marcada, que clínicamente es indolora. En la mayoría de los casos es unilocular aunque también puede presentarse de forma multilocular. Suele asociarse a elementos dentarios retenidos, también puede haber desplazamiento de los dientes vecinos y del conducto dentario inferior. Clínicamente el QOO puede tener una presentación variable. En la mayoría de los casos no presentan sintomatología, sin embargo se pudiera presentar dolor, infección y expansión ósea de la zona afectada. Entre las características macroscópicas presenta un lumen lleno de un material grueso o cremoso, mismo que corresponde a queratina.

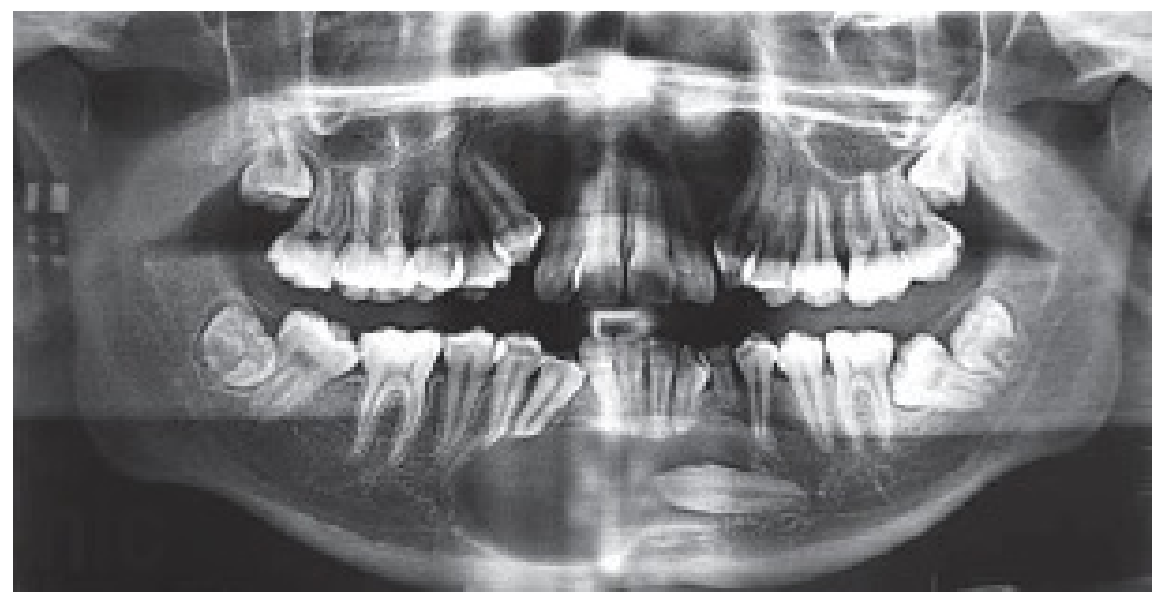

Figure 3: Ortopantomografía donde se observa una imagen radiolúcida unilocular, de bordes bien definidos, que desplaza algunas raices dentales. Se presenta desde la zona de premolares derechos a la zona de premolares contralaterales, con inclusion dental de canino inferior izquierdo.

Entre los diagnósticos diferenciales siempre debe considerarse el quiste dentígero, y el queratoquiste odontogénico (tumor odontogénico queratinizante).

Sus características inmunohistoquímicas demuestran que posee poco potencial de proliferación.No se ha reportado la tasa de transformación maligna de este tipo de lesiones. Han sido pocos los casos donde se ha observado este comportamiento y en ellos el crecimiento tumoral sólo pudo observarse histológicamente en la transición y cambios displásicos en la membrana quística. 


\begin{tabular}{|c|c|c|}
\hline Feature ${ }^{[2,3,7,11,12]}$ & OOC & OKC \\
\hline $\begin{array}{l}\text { Age } \\
\text { Gender } \\
\text { Association with impacted teeth (\%) } \\
\text { Association with NBCCS } \\
\text { Multiplicity } \\
\text { Location }\end{array}$ & $\begin{array}{l}3-4^{\text {th }} \text { decade } \\
\text { Male }>\text { female } \\
46.5-75 \\
\text { No } \\
\text { Rare } \\
\text { Posterior } \\
\text { mandible }\end{array}$ & $\begin{array}{l}2-3^{\text {rd }} \text { decade } \\
\text { Male }>\text { female } \\
25-40 \\
\text { Yes } \\
\text { Seen } \\
\text { Posterior } \\
\text { mandible }\end{array}$ \\
\hline Radiographic features $^{[2,3,7,11,12]}$ & $\begin{array}{l}\text { Usually } \\
\text { unilocular }\end{array}$ & $\begin{array}{l}\text { Unilocular or } \\
\text { multilocular }\end{array}$ \\
\hline $\begin{array}{l}\text { Root resorption } \\
\text { Bone expansion }\end{array}$ & $\begin{array}{l}\text { Not seen } \\
\text { Seen }\end{array}$ & $\begin{array}{l}\text { Seen } \\
\text { Not seen }\end{array}$ \\
\hline Histopathologic feature ${ }^{[2,3,7,11,12]}$ & Orthokeratinized & Parakeratinized \\
\hline $\begin{array}{l}\text { Surface corrugation } \\
\text { Basal cell palisading } \\
\text { Basal cell budding } \\
\text { Recurrence rate }(\%) \\
\text { Treatment }\end{array}$ & $\begin{array}{l}\text { Not seen } \\
\text { Not seen } \\
\text { Not seen } \\
2.2 \\
\text { Simple } \\
\text { enucleation }\end{array}$ & $\begin{array}{l}\text { Seen } \\
\text { Seen } \\
\text { Seen } \\
42.6 \\
\text { Wide excision }\end{array}$ \\
\hline
\end{tabular}

NBCCS: Nevoid basal cell carcinoma syndrome, 00C: Orthokeratinized

odontogenic cyst, OKC: Odontogenic keratocyst

Figure 4: Comparación de quiste odontogénico ortoqueratinizado y queratoquiste odontogénico

\section{CONCLUSIÓN}

El quiste odontogénico ortoqueratinizado es una entidad poco descrita; sin embargo, debemos considerarla como diagnóstico diferencial de lesiones como el quiste dentígero y el tumor odontogénico queratinizante, ya que las características clínicas y sobre todo radiológicas son muy similares. Es imprescindible tener el diagnóstico histopatológico antes de realizar cualquier procedimiento para evitar sobretratar esta lesión, mejorando así el pronóstico y recuperación de los pacientes. Los diferentes estudios realizados reflejan que las características histológicas, patogénesis y el comportamiento clínico es muy diferente respecto al tumor odontogénico queratinizante, por lo que reportarlo ayudaría a poder valorar el comportamiento clínico en nuestras poblaciones, con el objetivo de mejorar tratamientos y dar mejores pronósticos a nuestros pacientes. 


\section{REFERENCIAS BIBLIOGRÁFICAS}

1. Romero Jasso, G., \& Vargas López, D. (2016). Quiste odontogénico ortoqueratinizado. Reporte de un caso. Revista de la Asociación Dental Mexicana, 73(1), 23-27.

2. Durán, A. C.,et al. (2017). Quiste odontogénico ortoqueratinizado. Revista Mexicana de Cirugía Bucal y Maxilofacial, 13(2), 65-69.

3. Ortiz, L. V. F., \& Vega, C. P. P. (2018). Frecuencia de quistes odontogénicos en pacientes de la Facultad de Odontología, Universidad Nacional de Colombia. Universitas Odontológica, 37(79), 11.

4. Kamat, M., et al. (2018). Orthokeratinized odontogenic cyst with calcification: A rare case report of a distinct entity. Journal of oral and maxillofacial pathology : JOMFP, 22( 1), 20-23.

5. Shetty, D. C., et al. (2016). "Orthokeratinized odontogenic cyst masquerading as dentigerous cyst." International Journal of Applied and Basic Medical Research 6.4: 297. 
